\title{
DNA assembly with error correction on a droplet digital microfluidics platform
}

\author{
Yuliya Khilko ${ }^{1,2}$, Philip D. Weyman ${ }^{3}$, John I. Glass ${ }^{3}$, Mark D. Adams ${ }^{3}$, Melanie A. McNeil ${ }^{2}$ and Peter B. Griffin ${ }^{\text {1* }}$
}

\begin{abstract}
Background: Custom synthesized DNA is in high demand for synthetic biology applications. However, current technologies to produce these sequences using assembly from DNA oligonucleotides are costly and labor-intensive. The automation and reduced sample volumes afforded by microfluidic technologies could significantly decrease materials and labor costs associated with DNA synthesis. The purpose of this study was to develop a gene assembly protocol utilizing a digital microfluidic device. Toward this goal, we adapted bench-scale oligonucleotide assembly methods followed by enzymatic error correction to the Mondrian ${ }^{\mathrm{TM}}$ digital microfluidic platform.

Results: We optimized Gibson assembly, polymerase chain reaction (PCR), and enzymatic error correction reactions in a single protocol to assemble 12 oligonucleotides into a 339-bp double- stranded DNA sequence encoding part of the human influenza virus hemagglutinin (HA) gene. The reactions were scaled down to 0.6-1.2 $\mu \mathrm{L}$. Initial microfluidic assembly methods were successful and had an error frequency of approximately 4 errors/kb with errors originating from the original oligonucleotide synthesis. Relative to conventional benchtop procedures, PCR optimization required additional amounts of $\mathrm{MgCl}_{2}$, Phusion polymerase, and PEG 8000 to achieve amplification of the assembly and error correction products. After one round of error correction, error frequency was reduced to an average of 1.8 errors $\mathrm{kb}^{-1}$.

Conclusion: We demonstrated that DNA assembly from oligonucleotides and error correction could be completely automated on a digital microfluidic (DMF) platform. The results demonstrate that enzymatic reactions in droplets show a strong dependence on surface interactions, and successful on-chip implementation required supplementation with surfactants, molecular crowding agents, and an excess of enzyme. Enzymatic error correction of assembled fragments improved sequence fidelity by 2 -fold, which was a significant improvement but somewhat lower than expected compared to bench-top assays, suggesting an additional capacity for optimization.
\end{abstract}

Keywords: DNA, Gibson assembly, Digital microfluidics, Error correction

\section{Background}

Over the last decade, major research advances in genome sequencing (i.e. "DNA reading") are slowly being matched by advances in synthetic biology (i.e. "DNA writing") [1, 2]. Rapid advances in synthetic biology are fueling a demand for synthetic DNA that will only increase in the future. However, the ability to synthesize long DNA molecules in a short period of time without significant expense remains one of the main challenges in synthetic biology [3-5].

\footnotetext{
*Correspondence: griffin@stanford.edu

'Stanford Genome Technology Center, Stanford University, 3165 Porter Drive, Palo Alto, CA 94304, USA

Full list of author information is available at the end of the article
}

Gene synthesis is a costly and labor-intensive process. The cost of synthetic DNA is directly related to the cost of oligonucleotides, and a large amount of hands-on labor required for conventional oligonucleotide-based gene assembly is also a significant cost [6-8]. The cheapest oligonucleotides that can be purchased from commercial suppliers are usually unpurified and contain errors. Thus, the genes assembled from the unpurified oligonucleotides must be sequence verified to find a correct assembly. Implementation of an enzymatic error correction step greatly improves the sequence fidelity of the assemblies, which reduces the number of clones that have to be individually cloned and sequence verified [7, 9, 10]. Unfortunately, this extra error correction step also significantly increases the hands-on time required 
to complete assembly. Integration of digital microfluidics into DNA assembly coupled with error correction can potentially ease this labor burden by allowing for a "set up and walk away" approach to managing the entire process.

Digital microfluidics (DMF) is a technology based on the electrowetting phenomenon. The phenomenon describes a change of surface tension at a solid/liquid/ gas interface by application of an electric field [11, 12]. The voltage applied to the electrodes lowers the surface tension, which leads to a reduction of the contact angle and increases the wettability of the surface. Consequently, the liquid spreads over the surface where the voltage is applied. Thus, a hydrophobic surface becomes hydrophilic. By the application of a voltage on a dielectric surface, the liquids can be transported over the surface of a microfluidic cartridge.

In electrowetting on dielectric (EWOD) devices, a droplet is sandwiched between two hydrophobic plates and the remaining volume is filled with immiscible liquid, for example, a silicone oil (Fig. 1). The oil prevents evaporation of the aqueous droplets and facilitates transport. The bottom plate is the array of electrodes, which can locally control the surface tension by the application of a voltage. Digital microfluidic devices are completely programmable and do not require any pumps or valves to move the liquids. A cartridge can be inserted into a micro-controller that is operated by a software program [13-15]. The program turns the voltage on and off at certain electrodes, so the droplets can be directed anywhere on a chip. They can also be dispensed, transported, split, fused, mixed and held in certain regions.

Digital microfluidic devices are applicable for gene assembly because DNA is typically handled in microliter amounts. The microfluidic devices are capable of generating droplets in the microliter to picoliter range $[16,17]$. The microliter droplets act like reaction and transport vessels. The ability to program liquid handling operations such as dispense, transport, merge, mix, and split allows a researcher to automate and simplify the gene assembly process. Time-consuming steps like pipetting, transferring reagents, tube labeling, incubation at certain temperatures, and thermocycling can be replaced and performed by programmable droplet generation and routing over heater bars underneath the microfluidic cartridge. The sequential reactions can be performed on a single microfluidic cartridge without any human intervention [18]. Software automation programs can be designed to conduct multiple experiments in parallel. Since the devices are fully automated, the sources of human errors and labor costs can be greatly reduced. In addition, DNA assembly programs can be distributed between laboratories, so that scientists can share robust protocols.

Because DNA assembly and error correction reactions require the use of expensive enzymes, scaling down to smaller reaction volumes reduces reagent expenses. Due to the large surface-to-volume ratio, micro-droplet reactors have high heat and mass transfer rates. This makes it possible to increase kinetics and speed up reactions $[13,17,19]$. Integration of effective error correction procedures could permit DNA assembly on a single microfluidic cartridge without the need for expensive and lengthy sequence verification.

A number of DNA assembly protocols have been developed to date (Table 1). For the scope of this study, only assembly methods from oligonucleotides will be discussed. The most popular gene construction methods for microfluidic applications are polymerase-based and endonuclease-based assembly. Both approaches utilize oligonucleotides as DNA building blocks [20]. The polymerase-based assembly method utilizes the same approach as PCR [21-24]), but instead of using forward and reverse primers, oligonucleotides overlap and serve as templates for a complementary strand. The oligonucleotides are designed to be either a part of the top or the bottom DNA strand. In the first assembly cycle, oligonucleotides overlap partially, and the polymerase extends the complementary strand in a $5^{\prime}$ to $3^{\prime}$ direction. In the next cycle, the double-stranded DNA pieces are separated and hybridized to other oligonucleotides or assembled single-stranded fragments. The process of denaturation, annealing, and extension is repeated until the desired sequence has been built [25].

The studies shown in Table 1 utilized different types of microfluidics to perform DNA assembly. Among

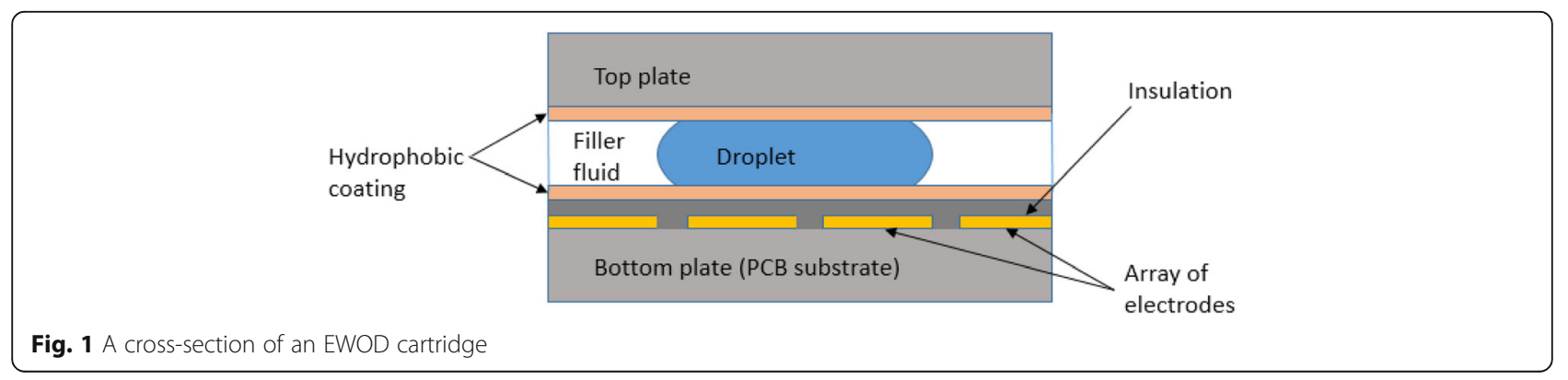


Table 1 Summary of microfluidic assembly methods

\begin{tabular}{|c|c|c|c|c|}
\hline Authors & Type of microfluidics & Assembly method & Assembly size & Error rates \\
\hline Kong et al. [22] & Droplet & Polymerase-based (PCA) & $500-1000 \mathrm{bp}$ & 1.78 errors $/ \mathrm{kb}$ \\
\hline Huang et al. [21] & Microchannel & Polymerase-based (PCA) & $760 \mathrm{bp}$ & 4.1 errors $/ \mathrm{kb}$ \\
\hline Quan et al. [23] & Microarray & Polymerase-based (PCA) & $500-1000 \mathrm{bp}$ & 1.9 errors/kb \\
\hline Tian et al. [24] & Microarray & Polymerase-based (PAM) & $14,500 \mathrm{bp}$ & 2.2 errors $/ \mathrm{kb}$ \\
\hline Linshiz et al. [48] & Chanel & $\begin{array}{l}\text { Exonuclease-based (Gibson) and } \\
\text { polymerase-based (IHDC) }\end{array}$ & $754 \mathrm{bp}$ & N/A \\
\hline Shih et al. [49] & Combined digital and droplet microfluidics & $\begin{array}{l}\text { Exonuclease-based assembly of } \\
\text { dsDNA (Gibson) }\end{array}$ & $2100 \mathrm{bp}$ & N/A \\
\hline Tangen et al. [50] & Droplets & $\begin{array}{l}\text { Polymerase-based (PCA) and } \\
\text { Exonuclease-based (Gibson) }\end{array}$ & $525 \mathrm{bp}$ & N/A \\
\hline Ben-Yehezkel et al. [18] & Digital microfluidics & Polymerase-based (POP) & $800 \mathrm{bp}$ & $2.22 \mathrm{errors} / \mathrm{kb}$ \\
\hline
\end{tabular}

those studies, only the work by Ben-Yehezkel et al. was conducted using digital microfluidics, the same type of microfluidics utilized in the present study. The group developed an innovation on the polymerase-based assembly method called programmable order polymerization (POP). The method was first successfully automated on the Mondrian $^{\text {tw }}$ microfluidic device. The assembly reaction proceeded to assemble the sequence from the inside out. In each of four phases, a double-stranded DNA (dsDNA) fragment was extended by a pair of oligonucleotides such that one oligonucleotide bound to each end of the sequence. Multiple rounds of thermocycling for each phase with an oligonucleotide pair ensured that most of the product was extended in each step. The group reported an error rate of 1 in $450 \mathrm{bp}\left(2.22\right.$ errors $\left.\mathrm{kb}^{-1}\right)$ for their assembly method, and the errors were identified as substitutions [18].

Whereas Ben-Yehezkel used four separate rounds of DNA polymerization to sequentially extend and assemble two DNA fragments in each round, we used a single "one-pot" assembly of 12 fragments in a single droplet and successfully assembled the complete sequence. In addition, we performed a round of error correction on the digital microfluidic device. At some point, a large number of DNA fragments in a one-pot reaction would lead to miss-hybridization, so it is interesting to contemplate a process that combines both these methods in a DNA assembly reaction to reduce the assembly time and errors even further.

In summary, the one-pot assembly method used in this manuscript is a one-step isothermal Gibson assembly developed at the J. Craig Venter Institute ([26]) and is distinctly different in process from the work described by Ben-Yehezkel et al. With this technique, double- or single-stranded DNA pieces are joined into longer fragments by three enzymes: T5 exonuclease, DNA polymerase, and Taq DNA ligase. The reagents are incubated at $50{ }^{\circ} \mathrm{C}$ for $0.5-1 \mathrm{~h}$ after which the assembled product is typically amplified by PCR [27]. Published protocols use multiple rounds of error correction after assembly and PCR to decrease the incidence of errors originating from the oligonucleotides [28]. Gibson assembly has been used successfully to assemble entire genes $(1.5-1.7 \mathrm{~kb})$ in a single step, and this method is arguably the most efficient to assemble genes from multiple oligonucleotides [28]. Using Gibson assembly, higher numbers of oligonucleotides can be assembled in a single reaction than by PCR assembly. For this reason, we decided to implement Gibson assembly on a DMF device.

To design a DNA assembly protocol for a programmable digital microfluidic device, we developed a process consisting of three major parts (Fig. 2). First, DNA oligonucleotides were assembled into a double-stranded DNA fragment. Second, the assembly was amplified by PCR, and third, errors from the original oligonucleotides were removed. We used Sanger DNA sequencing of the recovered, error-corrected products to verify the efficiency of the error correction process and develop an efficient DNA assembly and error correction protocol. The ultimate goal is to design a reliable and cost-effective DNA assembly protocol that will be widely applicable in biological research.

\section{Methods \\ DNA sequences and oligonucleotides}

Our 339-bp test assembly sequence comprised a partial sequence from the human influenza virus H9N2 hemagglutinin (HA) gene (283-bp, nt 211-493 of the HA coding region) flanked on each side by 8 -bp NotI restriction endonuclease sites and 20-bp homology regions to the pUC19 cloning vector. The 339-bp fragment was divided into 12 overlapping oligonucleotides (See Table 2). The final assembled test sequence is listed in Fig. 3.

\section{Mondrian $^{\mathrm{Tm}}$ digital microfluidics (DMF) device}

The main goal of this study was to develop a robust and reliable DNA assembly and error correction protocol for the Mondrian ${ }^{\text {TM }}$ DMF device (Illumina, Inc.). The whole protocol involved four consecutive enzymatic reactions. 


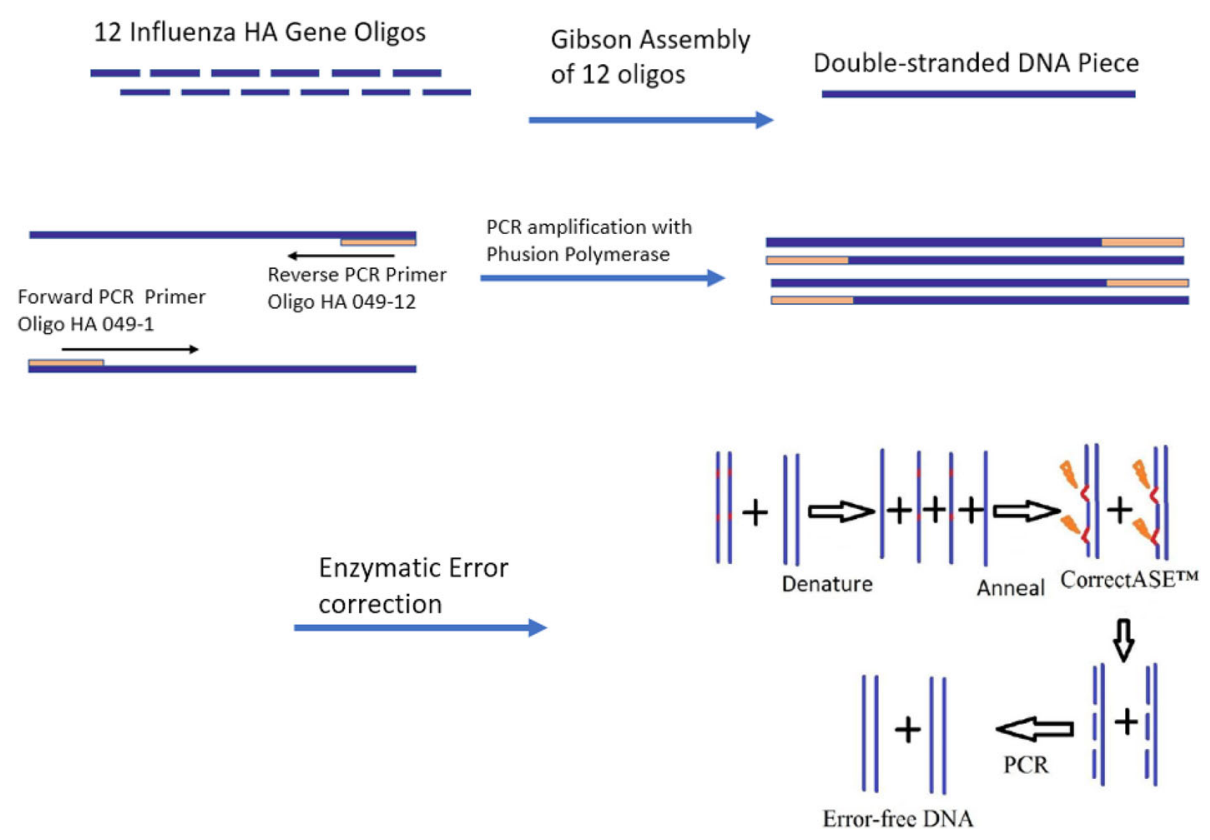

Fig. 2 A schematic of influenza HA gene assembly on DMF. This diagram shows the steps of the process which were all performed sequentially on a microfluidic cartridge. The steps are Gibson assembly of 12 oligonucleotides, PCR amplification of a double-stranded DNA piece, error removal using an error correction enzyme, and PCR amplification of corrected sequences

Prior to incorporating the four enzymatic steps of the gene assembly in a complete protocol, each enzymatic step was optimized individually. All liquid handling operations were programmed using the Application Development Environment software (Illumina, Inc.).

The Mondrian ${ }^{\text {Tw }}$ microfluidic system included a microcontroller that was connected to a computer and digital microfluidic cartridges that were inserted into the device. To observe the behavior of the droplets, a digital camera was mounted above the cartridge to produce a magnified image of the DMF cartridge onto a computer screen. The Mondrian ${ }^{\mathrm{Tx}}$ cartridge that was used in the experiments (Fig. 4a), consisted of two plates, a plastic top plate, and a printed circuit board (PCB) substrate. The area between the plates was filled with a 2 cSt silicone oil. As seen in Fig. 4b, the configuration of the

Table 2 Primers used in this study

\begin{tabular}{|c|c|}
\hline Primer Name & Primer Sequence $\left(5^{\prime}->3^{\prime}\right)$ \\
\hline Puc-049cloning-R & CCGGGTACCGAGCTCGAATTCACTG \\
\hline Puc-049cloning-F & GATCCTCTAGAGTCGACCTGCAGGC \\
\hline Puc19-5'F & TCCCAGTCACGACGTTGTAAAACGAC \\
\hline HA049-1 & CAGGTCGACTCTAGAGGATCGCGGCCGCGACACATGCACTATTGAAGGACTI \\
\hline HA049-2 & AGATCACAAGAAGGGTTACCATAGACAAGTCCTTCAATAGTGCATGTGTCGC \\
\hline HA049-3 & GTCTATGGTAACCCTTCTTGTGATCTGTTGTTGGGGGGAAGAGAATGGTCCT \\
\hline HA049-4 & TACAGCTGATGGTCTTTCAACGATGTAGGACCATTCTCTTCCCCCCAACAAC \\
\hline HA049-5 & ACATCGTTGAAAGACCATCAGCTGTAAATGGAACGTGTTACCCTGGGAATGT \\
\hline HA049-6 & GTGTTCTGAGTTCCTCTAAGTTTTCCACATTCCCAGGGTAACACGTTCCATT \\
\hline HA049-7 & GGAAAACTTAGAGGAACTCAGAACACTCTTTAGTTCCTCTAGTTCCTACCAA \\
\hline HA049-8 & ATTGTGTCTGGGAATATTTGGATTCTTTGGTAGGAACTAGAGGAACTAAAGA \\
\hline HA049-9 & AGAATCCAAATATTCCCAGACACAATCTGGAATGTGACTTACACTGGAACAA \\
\hline HA049-10 & GTAGAATGAATCTGAACATGATTTGCTTGTTCCAGTGTAAGTCACATTCCAG \\
\hline HA049-11 & GCAAATCATGTTCAGATTCATTCTACAGGAACATGAGATGGCTGACTCAAAG \\
\hline HA049-12 & GAATTCGAGCTCGGTACCCGGCGGCCGCTTTGAGTCAGCCATCTCATGTTCCT \\
\hline
\end{tabular}




\section{a}

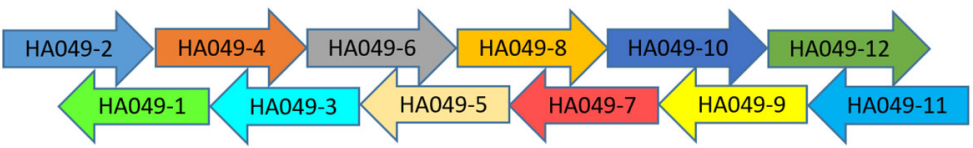

b

$>$ HA049_sequence

GAATTCGAGCTCGGTACCCGGCGGCCGCTTTGAGTCAGCCATCTCATGTTCCTGTAGAATGAATCT GAACATGATTTGCTTGTTCCAGTGTAAGTCACATTCCAGATTGTGTCTGGGAATATTTGGATTCTTT GGTAGGAACTAGAGGAACTAAAGAGTGTTCTGAGTTCCTCTAAGTTTTCCACATTCCCAGGGTAAC ACGTTCCATTTACAGCTGATGGTCTTTCAACGATGTAGGACCATTCTCTTCCCCCCAACAACAGAT CACAAGAAGGGTTACCATAGACAAGTCCTTCAATAGTGCATGTGTCGCGGCCGCGATCCTCTAGA GTCGACCTG

Fig. 3 Oligonucleotide alignment for the 339-bp test assembly sequence. a Arrangement of DNA oligonucleotides used for assembly of the HA049 sequence. b FASTA formatted HA049 sequence

DMF cartridge allowed eight processes to be performed in parallel. The reagents were loaded through $50 \mu \mathrm{L}$ or $10 \mu \mathrm{L}$ ports on the cartridge top plate, and the samples were withdrawn through other ports. There were also seven reservoirs dedicated for the collection of waste droplets. The microfluidic cartridge had three heater bars that contacted the back of the $\mathrm{PCB}$, which were used to set temperatures for the enzymatic reactions. Additionally, an area of the cartridge could be cooled down with a Peltier device. Fig. 4c shows a close-up view of one lane with three different temperature zones, which were maintained during reactions using the heaters and the cooler. The device was operated by the Application Development Environment (ADE) software.

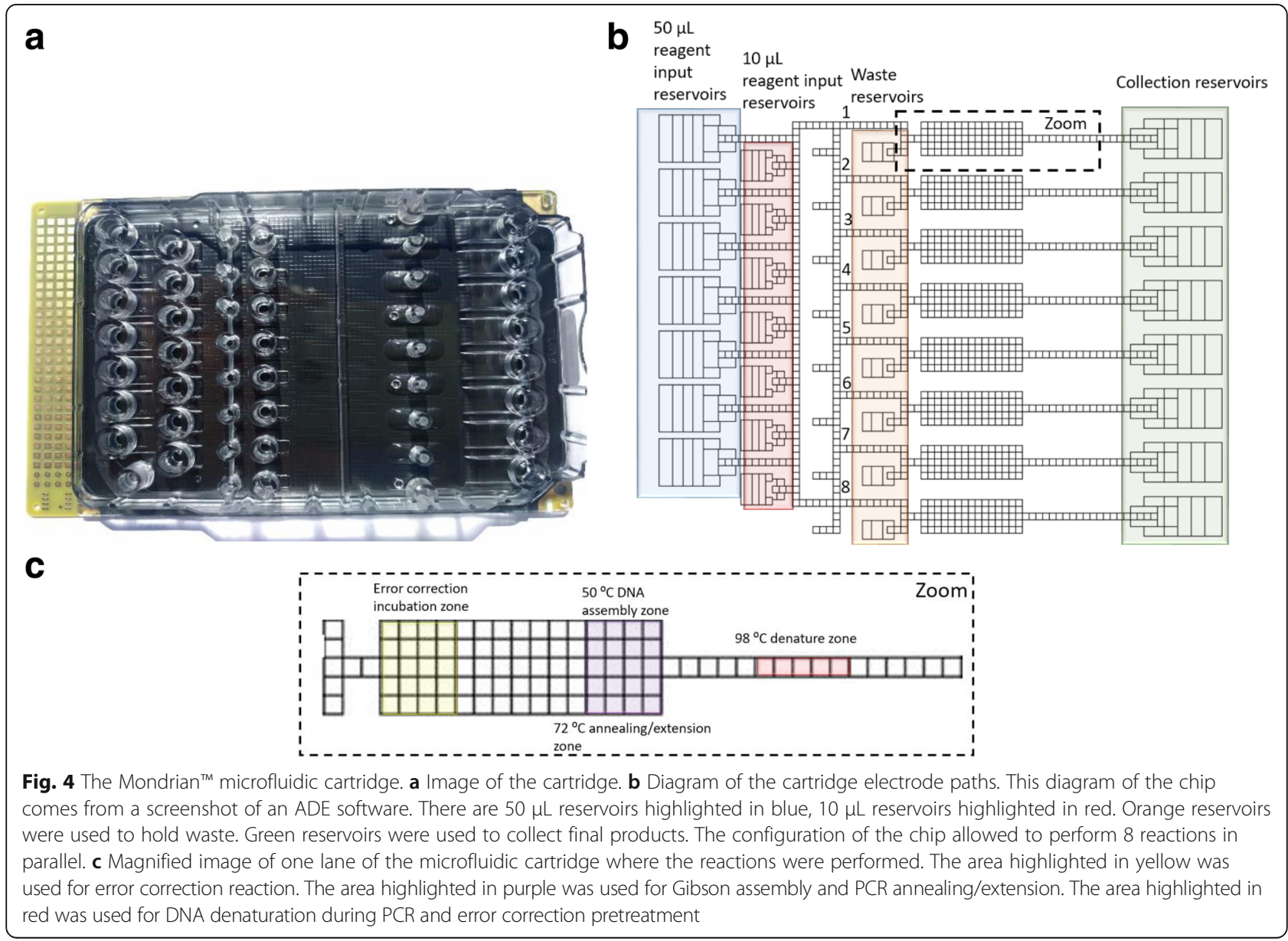


Prior to each experiment, a program was designed to direct droplets through the liquid handling operations. The device was operated at voltages between $90 \mathrm{~V}$ and $300 \mathrm{~V}$ and at a frequency of $30 \mathrm{~Hz}$.

The liquid volumes of $0.3,0.6$, and $1.2 \mu \mathrm{L}$ were generated and manipulated on the microfluidic cartridge. To dispense a $0.3 \mu \mathrm{L}$ or $0.6 \mu \mathrm{L}$ droplet, three electrodes adjacent to the reagent input port were activated, which caused the liquid to spread over three electrodes (Fig. 5a). The electrode \# 2 was switched off to obtain a $0.3 \mu \mathrm{L}$ droplet (Fig. 5b). The double $0.6 \mu \mathrm{L}$ droplet was dispensed by turning off the electrode \#3 (Fig. 5c). To create a $1.2 \mu \mathrm{L}$ droplet, two $0.6 \mu \mathrm{L}$ droplets are brought next to each other and separated by one inactive electrode as shown in Fig. $5 \mathrm{~d}$. Then the electrode between the two $0.6 \mu \mathrm{L}$ droplets was turned on, merging both into one $1.2 \mu \mathrm{L}$ droplet (Fig. 5e). Refer to Additional file 1: Video 1 to see the liquid handling operation described here. Materials to see all liquid handling operations used in present work.

\section{Optimization of microfluidic PCR}

Each on-chip PCR reaction contained 1X HF Phusion buffer, detergent-free (Thermo Fisher Scientific), $0.8 \mu \mathrm{M}$ forward and reverse primers, $1.75 \mathrm{ng} / \mu \mathrm{L}$ HA-049 DNA template (plasmid-cloned HA-049 sequence), $0.1 \mathrm{U} \mu \mathrm{L}^{-}$

${ }^{1}$ Phusion polymerase (Thermo Fisher Scientific). The reactions were set up to allow the addition of $1 \mathrm{mM}$ $\mathrm{MgCl}_{2}, 1.25 \mathrm{mM}$ PEG 8000, $0.2 \mathrm{mM}$ NAD, $2 \mathrm{mM}$ DTT to the reaction mixture or the combination of $1.25 \mathrm{mM}$ PEG 8000 and $1 \mathrm{mM} \mathrm{MgCl}, 0.2 \mathrm{mM} \mathrm{NAD}$, and $2 \mathrm{mM}$ DTT. Final concentrations in the reaction droplets are given for all reagents.
An automation program for the DMF was developed to perform microfluidic PCR amplification experiments. The reactions were carried out in $1.2 \mu \mathrm{L}$ droplets. The droplets were brought to the PCR area of the chip, which consisted of two temperature zones. The denaturation zone was set to $98{ }^{\circ} \mathrm{C}$, and the annealing/extension zone was set to $72{ }^{\circ} \mathrm{C}$.

The thermocycling was performed at a reduced voltage $(90 \mathrm{~V})$, which eliminated nonspecific adsorption of polymerase on the microfluidic surface and reduced spurious bubble formation at high temperatures [18, 27, 29-32]. An initial denaturation was performed by moving the droplets to the $98{ }^{\circ} \mathrm{C}$ zone where they were held for $30 \mathrm{~s}$. Then thirty PCR cycles were performed by cycling the droplets from $98{ }^{\circ} \mathrm{C}$ to $72{ }^{\circ} \mathrm{C}$ at 1.5 s/electrode, and from $72{ }^{\circ} \mathrm{C}$ to $98{ }^{\circ} \mathrm{C}$ at 1 s/electrode. Annealing/extension of the droplets was done by switching on/off voltage of the area of three electrodes every half of a second for $20 \mathrm{~s}$, and denaturation was performed by holding the droplets at $98{ }^{\circ} \mathrm{C}$ for $10 \mathrm{~s}$. After 30 cycles of PCR, DNA was held for $10 \mathrm{~min}$ at $72{ }^{\circ} \mathrm{C}$ to allow a final extension. Then, the voltage was switched back to $300 \mathrm{~V}$, so that the samples could be transported to the collection reservoirs.

\section{Optimization of microfluidic Gibson assembly}

In each experiment, $50 \mu \mathrm{L}$ master mixes were made from fresh reagents and prepared according to previously published Gibson Assembly protocols [33] with additional modifications described below. Assembly, oligonucleotide, and PCR master mixes were prepared at $2 \mathrm{X}$ concentrations such that once two equal size droplets were merged, the final enzyme mixtures would

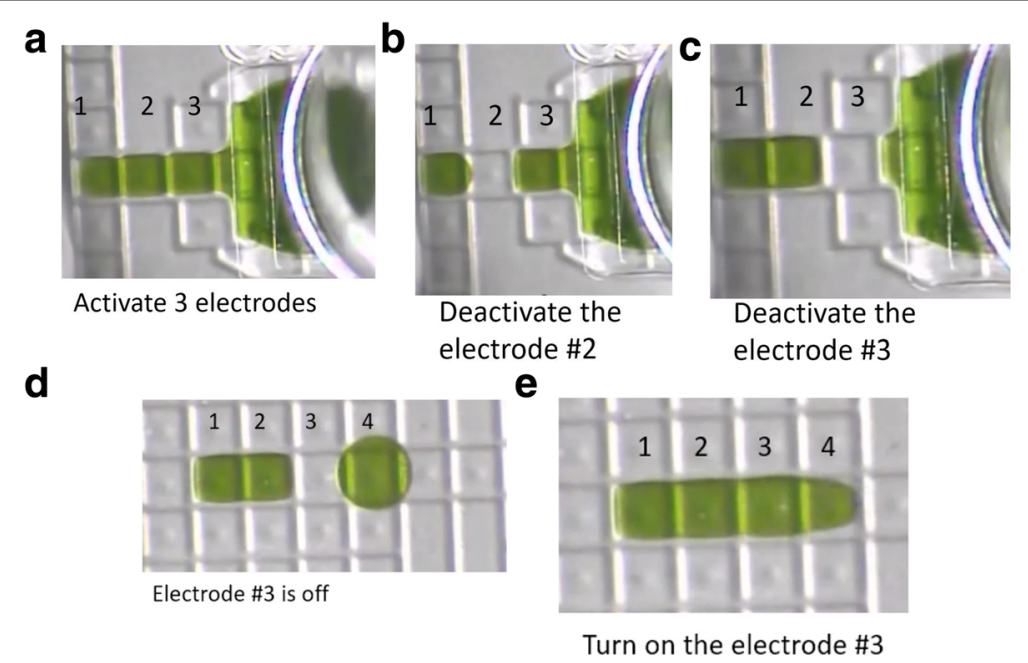

Fig. 5 Generation of $0.3,0.6$, and $1.2 \mu \mathrm{L}$ droplets on DMF. a Stretching the liquid over three electrodes. $\mathbf{b}$ Generation of $0.3 \mu \mathrm{L}$ droplet. $\mathbf{c}$ Generation of $0.6 \mu \mathrm{L}$ droplet. $\mathbf{d}$ Two $0.6 \mu \mathrm{L}$ droplets separated by 1 electrode. e $1.2 \mu \mathrm{L}$ droplet resulted from merging two $0.6 \mu \mathrm{L}$ droplets 
be at the correct $1 \mathrm{X}$ concentration. The oligo master mix containing a mixture of all oligonucleotides was prepared by diluting a $1 \mu \mathrm{M}$ stock solution in DI water containing $0.01 \%$ Tween 20 . The surfactant was a necessary component to reduce the surface tension, which facilitated droplet dispensing and movement. The amount of surfactant required was determined for each master mix. The enzymes suspended in storage buffers contained stabilizers. It was observed that the droplets with enzyme solutions were easily dispensed and manipulated on a cartridge without any additional surfactant. Thus, the assembly master mix and PCR master mix did not contain Tween 20. The final (1X) concentrations of reagents in the assembly reaction were $1 \mathrm{X}$ isothermal (iso) buffer, $0.05 \mathrm{U} \mu \mathrm{L}^{-1}$ of Phusion polymerase, $4 \mathrm{U} \mu \mathrm{L}^{-1}$

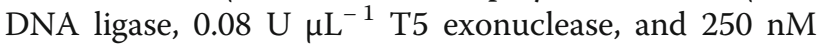
oligonucleotides.

To perform DNA assembly experiments, an automation program was created. The temperature in the assembly area was set to $50{ }^{\circ} \mathrm{C}$. Next, $0.3 \mu \mathrm{L}$ droplets containing oligonucleotides were dispensed. The droplets were transported to a waiting area where they were held while another dispenser generated 2X Gibson master mix droplets. The oligonucleotide and Gibson master mix droplets were merged to obtain a double $0.6 \mu \mathrm{L}$ droplet and brought to the assembly area where they were incubated for $15-60 \mathrm{~min}$ at $50{ }^{\circ} \mathrm{C}$. To ensure adequate mixing, the droplets were moved up and down over 4 electrodes. When the reaction was finished, the assembly droplets were merged with $0.6 \mu \mathrm{L}$ PCR droplets, so the total volume of each droplet became $1.2 \mu \mathrm{L}$. The polymerase chain reaction was performed as described above. After PCR, the products were diluted. To perform dilutions, a dispenser containing DI water and $0.05 \%$ Tween 20 generated $0.6 \mu \mathrm{L}$ droplets. Then, the droplets were merged with the assembly droplets, mixed, and split into two equal size droplets. This step was iterated to achieve the desired dilutions. When assembly time was variable, $0.6 \mu \mathrm{L}$ droplets containing both the oligonucleotides and Gibson assembly reagents were held in a waiting area, and two droplets were moved to the assembly incubation zone in $15 \mathrm{~min}$ increments. This way, each condition was tested twice in two different experimental droplets.

\section{Optimization of enzymatic error correction}

The optimization of enzymatic error correction step was performed using a mix of two equal molar amounts of 339-bp PCR products. Sequences were amplified from two DNA templates. The first template had a completely correct sequence and the other had a mutation approximately in the middle of the 339-bp sequence. If the error correction reaction was successful, two DNA bands were visualized on an agarose gel corresponding to the original size (339-bp) and the cleaved size (approximately 170-bp). In case of a failure, only one 339-bp band was visible. Preliminary experiments demonstrated that a microfluidic error correction reaction with standard benchtop reagents was not successful due microfluidic surface interactions and nonspecific adsorption of CorrectASE ${ }^{\mathrm{mm}}$. To test the hypothesis of CorrectASE ${ }^{\mathrm{mow}}$ adsorption on the droplet oil/water interface, the mix of DNA was treated with additional reagents. The reactions were performed with extra CorrectASE ${ }^{\mathrm{mm}}, 0.01 \%$ Tween 20, $1.25 \mathrm{mM}$ PEG 8000, and $2.5 \mathrm{mM} \mathrm{MgCl}_{2}$ to determine which could improve reaction performance.

\section{Protocol for DNA assembly with error correction}

The protocol consisted of four consecutive enzymatic reactions. The process started with Gibson assembly that was carried out for $60 \mathrm{~min}$. Then, the assembly products were amplified in 30 PCR cycles. Next, DNA was treated with CorrectASE ${ }^{\mathrm{m}}$ for $60 \mathrm{~min}$. The error correction products were amplified in a second PCR. According to this protocol, the final concentrations of reagents in Gibson assembly reaction were $1 \mathrm{X}$ isothermal (iso) buffer, 0 .

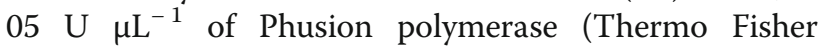
Scientific), $4 \mathrm{U} \mu \mathrm{L}^{-1}$ DNA ligase (NEB), $0.08 \mathrm{U} \mu \mathrm{L}^{-1} \mathrm{~T} 5$ exonuclease (NEB), and $50 \mathrm{nM}$ oligonucleotides (IDT DNA). After assembly, the product was diluted with 0 . 01\% Tween 20 (Sigma Aldrich) by 8-fold. Diluted assemblies were merged with equal size droplets of PCR mas-

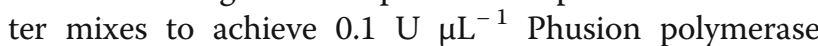
(Thermo Fisher Scientific), 1X HF detergent-free buffer (Thermo Fisher Scientific), $0.25 \mathrm{mM}$ of each dNTP (Thermo Fisher Scientific), $0.8 \mu \mathrm{M}$ of forward and reverse primers (IDT DNA, 0.625 mM PEG 8000 (Sigma), $0.5 \mathrm{mM} \mathrm{MgCl} 2$ (Thermo Fisher Scientific) in the reactions. After amplification, two of the eight droplets were recovered from the chip, and the rest of the droplets were diluted by 2 -fold with $0.01 \%$ Tween 20 solution to continue to the error correction step.

The EC denature/anneal step of the protocol was implemented to expose the errors in DNA sequence for further CorrectASE ${ }^{\mathrm{mm}}$ treatment. During the denaturation step, DNA was diluted to $20-25 \mathrm{ng} \mu \mathrm{L}^{-1}$ in $1 \mathrm{X}$ CorrectASE ${ }^{\mathrm{rm}}$ buffer and incubated at $98{ }^{\circ} \mathrm{C}$ for $2 \mathrm{~min}, 25^{\circ} \mathrm{C}$ for $5 \mathrm{~min}$, and $37{ }^{\circ} \mathrm{C}$ for $5 \mathrm{~min}$. Then, the droplets were merged with CorrectASE $^{\mathrm{ma}}$ master mix to a final concentration of $2 \mathrm{X}$ CorrectASE $^{\text {mi }}$ (Invitrogen), $0.01 \%$ Tween 20 (Sigma Aldrich), and $2.5 \mathrm{mM}$ PEG 8000 (Sigma). The master mixes contained double amounts of reagents to obtain $1 \mathrm{X}$ concentration after the equal size droplets were merged. The reagents were loaded on a DMF cartridge into dedicated dispensers as prescribed by the automation program. All master mixes except CorrectASE ${ }^{\mathrm{ma}}$ were loaded on the cartridge at the beginning of the process. To ensure that the enzyme stayed active, CorrectASE ${ }^{\text {tu }}$ 
was loaded into the dispenser three minutes before it was to be used by the program. At the end of the process, all droplets were collected in $20 \mu \mathrm{L}$ water containing $0.05 \%$ Tween 20 and retrieved from the device manually.

\section{Cloning and sequencing of assembled and amplified products}

Recovered products were brought up to $50 \mu \mathrm{L}$ in water and an equal volume of Agencourt AMPure XP beads (Beckman Coulter) was added and mixed. After 5 min incubation to bind DNA to the beads, the tube was placed on a magnet and allowed to settle for $5 \mathrm{~min}$. The supernatant was removed and the beads were washed two times with $80 \%$ ethanol. After a final 5 min incubation with the caps open to allow the beads to dry, the DNA was eluted in $15 \mu \mathrm{L}$ $10 \mathrm{mM}$ TRIS buffer ( $\mathrm{pH} 8.5$ ).

The purified products were assembled into a pUC19 vector that was amplified by primers Puc-049cloning- $\mathrm{R}$ + Puc-049cloning-L (Table 2) using OneTaq polymerase (NEB). Assembly of the product into the pUC19 vector was by Gibson assembly [7, 8, 33], assembly reactions were electroporated into E. coli strain Epi300 (Epicentre) , and resulting clones were selected on LB plates containing ampicillin at $100 \mu \mathrm{g} \mathrm{mL} \mathrm{m}^{-1}$. Colonies were screened using $20 \mu \mathrm{L}$ colony PCR reactions with primers pUC19-5'F and pUC19-3'R (OneTaq, NEB). Colonies containing a plasmid with an insert sequence of 339bp were grown overnight in $5 \mathrm{~mL} \mathrm{LB}$ broth and purified using the QIAprep miniprep kit (Qiagen). The insert sequences of the resulting plasmids were analyzed by Sanger DNA sequencing. For each treatment, 10-20 independent clones were sequenced using the pUC19-5'F primer.

\section{Data analysis}

Samples recovered from Lanes 1 and 2, 3-8, which corresponded to assembly-only and EC treatments, respectively, were pooled and analyzed by DNA gel electrophoresis on a $2 \%$ agarose gel, and using the $1 \mathrm{~Kb}$ plus DNA ladder (Invitrogen) as a size standard. The indication of a successful experimental run was the presence of a 339-bp band. For the in-depth error analysis, the samples were cloned into pUC19 vectors and Sanger sequenced. Sequencing data was analyzed by aligning sequencing output files with the template DNA (Additional file 2). Each sequence alignment was inspected for errors in the newly assembled sequence. The errors were categorized in three groups: deletions, insertions, and substitutions. The sequences that had misincorporated oligonucleotides were treated as "misassemblies". The error frequency per $1 \mathrm{~kb}$ (f) was calculated using Eq. 1 [34].

$$
\mathrm{f}=\frac{\sum_{\mathrm{i}}^{\mathrm{n}} \mathrm{x}_{\mathrm{i}} \times 1000}{\mathrm{n} \times \mathrm{l}_{\mathrm{i}}}
$$

where $\mathrm{x}$ is the number of errors in a single clone, $\mathrm{n}$ is the number of sequenced clones not including clones with mis-assemblies, and 1 is the length of a sequence in bases.

\section{Results}

\section{Optimization of microfluidic PCR}

Optimization of PCR on DMF demonstrated that the additives improved amplification efficiency. Control samples, which contained $0.1 \mathrm{U} \mu \mathrm{L}^{-1}$ of Phusion polymerase, did not show any bands on the agarose gel (data not shown). On the other hand, PCR that contained the iso buffer used for DNA assembly resulted in the desired 339-bp bands. To determine the components of the iso buffer that contributed to the successful PCR reaction, we tested each component individually and in combination. When PEG 8000, DTT, NAD, and $\mathrm{MgCl}_{2}$ were added separately to the reaction, only PEG 8000 demonstrated some amplification of DNA template, but the result was not as good as PCR supplemented with the iso buffer (data not shown). Based on these results PEG 8000 was combined with either NAD, DTT, or $\mathrm{MgCl}_{2}$ to find out if DNA would be amplified at the same level as with the iso buffer. As seen in Fig. 6, the combination of $1.25 \mathrm{mM}$ PEG 8000 and $1 \mathrm{mM}$ $\mathrm{MgCl}_{2}$ showed comparable band intensity as the iso buffer. This result demonstrated that microfluidic PCR must be performed with an excess of Phusion enzyme and supplemented with additional $\mathrm{MgCl}_{2}$ and PEG 8000 .

Multiple methods to reduce biofouling in microfluidics have been tested in this work. The only method that improved PCR yield and transport of droplets was the reduction of the electrowetting voltage from $300 \mathrm{~V}$ to $90 \mathrm{~V}$ during high-temperature PCR [18]. For more

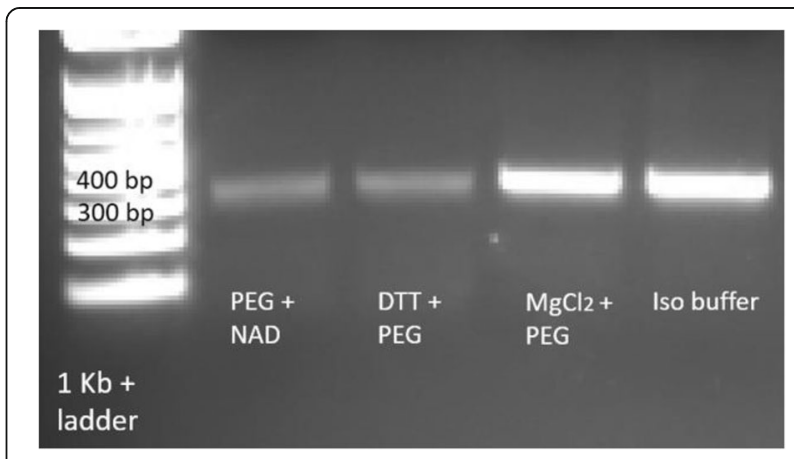

Fig. 6 On-chip polymerase chain reaction performed with two components of the iso buffer as described in the text. DNA from the reactions was separated by agarose gel electrophoresis on a $2 \%$ agarose gel 
information refer to the Additional file 3: Video 2 included in Additional files.

\section{Optimization of microfluidic Gibson assembly}

The first group of experiments tested optimum reaction time for oligonucleotide assembly. When we tested reaction times spanning 15-60 min, the bands for all tested times were of similar brightness (Fig. 7), suggesting the oligonucleotides were assembled in the 15-60 min time period.

Figure 8 demonstrates the results of microfluidic assembly experiments with a dilution of assembly constructs prior to PCR. Dilution of the assembly constructs from 2-fold to 16-fold resulted in comparable amounts of the PCR product. However, 16-fold was the maximum dilution rate that could be achieved before the PCR template was too dilute to amplify. A dilution rate greater than 32-fold did not result in amplification of the assembly product.

To investigate if the concentration of oligonucleotides in the assembly reaction could influence the fidelity of assembly constructs, two sets of samples obtained by the assembly of $50 \mathrm{nM}$ or $250 \mathrm{nM}$ oligonucleotides were sequenced. The average error rate from five separate runs for each oligonucleotides concentration is shown in Fig. 9. It was determined that the average error rate for $250 \mathrm{nM}$ and $50 \mathrm{nM}$ oligonucleotides was similar, at 3.15 errors $\mathrm{kb}^{-1}$ and 2.94 errors $\mathrm{kb}^{-1}$, respectively.

Single-base deletions comprised the bulk of errors. There was no preference for errors to occur between A/ $\mathrm{T}$ or $\mathrm{C} / \mathrm{G}$ bases. Both sets of samples had comparable percentages of deletions and the same amount of multiple-base deletions. The assembly of $50 \mathrm{nM}$ oligonucleotides resulted in $80 \%$ deletion errors, whereas $250 \mathrm{nM}$ assembly had $83 \%$ deletions, with the remainder being multiple base deletions, insertions or substitutions.

\section{Optimization of enzymatic error correction}

An optimization of the error correction reaction was conducted to determine the reagents that reduce adsorption of CorrectASE ${ }^{\mathrm{m}}$ on the oil/water interface and improve the performance of CorrectASE $E^{\mathrm{m}}$ enzyme. The reactions were supplemented with either PEG 8000, Tween 20, and excess CorrectASE ${ }^{\mathrm{TM}}$ or combination of the additives. Our test for CorrectASE ${ }^{\mathrm{mm}}$ activity was to add a mixture of two PCR products with one containing a nucleotide mismatch in the sequence relative to the other at approximately the midpoint of the sequence. Thus, successful error correction led to cleavage of the full-length product and resulted in two bands (339-bp and 170-bp) on the agarose gel with comparable intensities. As seen in Fig. 10, the presence of $0.01 \%$ Tween 20, 2X CorrectASE ${ }^{\mathrm{m}}$ and $1.25 \mathrm{mM}$ of PEG 8000 in the reaction droplet gave the most even brightness in both bands on the agarose gel.

\section{Validation of DMF protocol for assembly with error correction}

The error analysis of DNA assembly of 12 oligonucleotides followed by CorrectASE ${ }^{\mathrm{Tm}}$ treatment is shown in Fig. 11 and Additional file 2. The average error frequency of assembly samples from three separate runs was found to be about 4 errors $\mathrm{kb}^{-1}$, which corresponds to what is widely reported for phosphoramidite DNA synthesis chemistry, where error rates of approximately 1:200 are typical. The average error frequency of the samples after error correction was about 2 errors $\mathrm{kb}^{-1}$, which corresponds to an average error reduction by 2 fold. The average error reduction using a conventional benchtop protocol with the same sequence was found to be about 10-fold (data not shown).

As seen in Table 3, the enzyme was effective in removing deletion and insertion errors but failed to remove substitutions. Overall, error correction was successful, and in all three experiments about half of the sequenced clones were found to be error-free.

\section{Discussion \\ Optimization of microfluidic PCR}

The results of the microfluidic PCR experiments demonstrated that due to the high surface-to-volume ratio, reactions performed on the microfluidic device show a

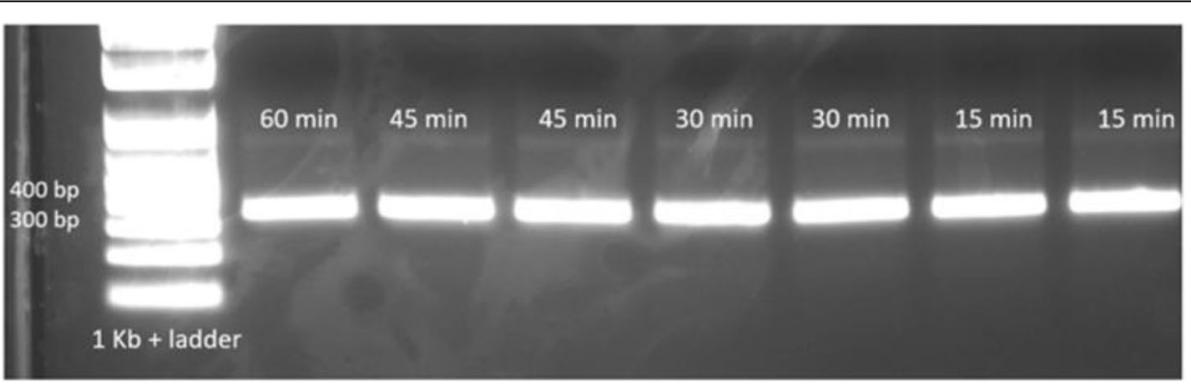

Fig. 7 On-chip oligonucleotide assembly and PCR amplifications testing different assembly reaction durations. DNA from the reactions was separated by agarose gel electrophoresis on a $2 \%$ agarose gel 
a

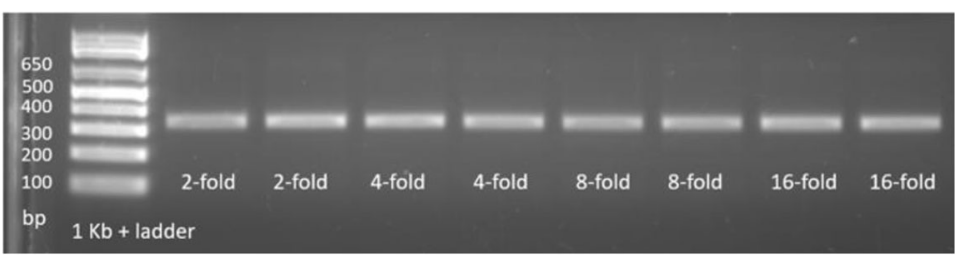

b

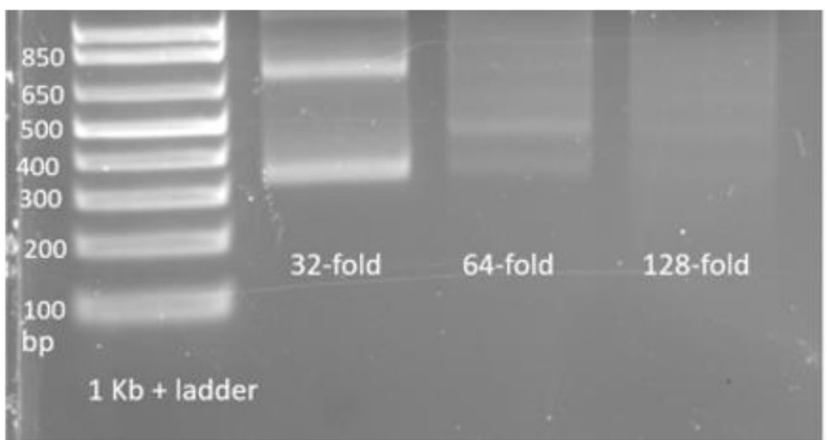

Fig. 8 Dilution of the oligonucleotide assembly product (assembled with $50 \mathrm{nM}$ each oligo) prior to PCR. a 2 to 16 -fold and $\mathbf{b} 32$ to 128 -fold. After dilution and PCR, products were separated by agarose gel electrophoresis on $2 \%$ agarose gels

strong dependence on surface interactions. Protein molecules can adsorb at the oil/water interface, which reduces the surface tension over time [27, 35]. Additionally, adsorption of a protein at the droplet aqueous/oil interface could facilitate segregation of hydrophobic groups that may lead to change in protein conformation and inactivation. At high temperatures, the exposed hydrophobic groups of the protein could lead to protein denaturation. The combined effect of protein adsorption and denaturation could reduce the amount of available enzyme and decrease reaction efficiency. It has been reported previously that to achieve amplification efficiency similar to a benchtop PCR, the amount of polymerase must be increased up to 10 -fold in microfluidic droplets $[36,37]$. The results of PCR experiments presented here demonstrated that sufficient and repeatable PCR amplification could be achieved with a 5-fold increase of Phusion polymerase.

The efficiency and specificity of PCR are affected by the $\mathrm{Mg}^{2+}$ concentration. Magnesium ions help the polymerase to fold in the active conformation [38]. Also, $\mathrm{Mg}^{2+}$ stabilizes dsDNA and increases the melting temperature $\left(\mathrm{T}_{\mathrm{m}}\right)$ of primers. Thus, it is crucial to have the correct amount of free magnesium, and this concentration must often be optimized for each primer pair. It has been observed that the concentration of free

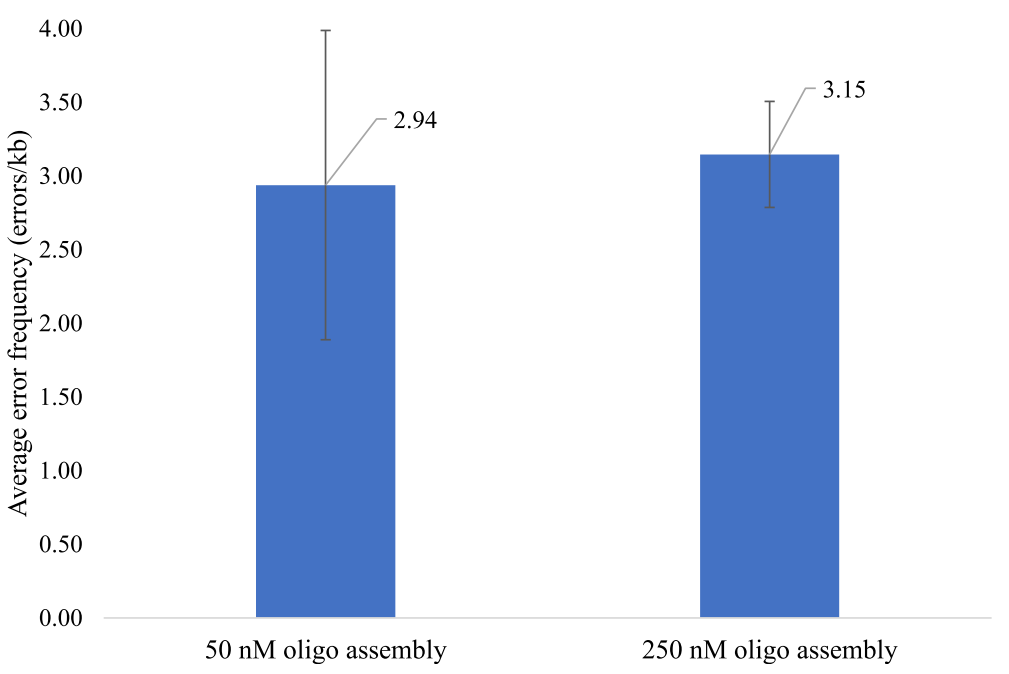

Fig. 9 Average error frequency for sequences assembled from $250 \mathrm{nM}$ and $50 \mathrm{nM}$ oligonucleotides. Average error frequency from five independent experiments is plotted with error bars indicating one standard deviation from the mean 


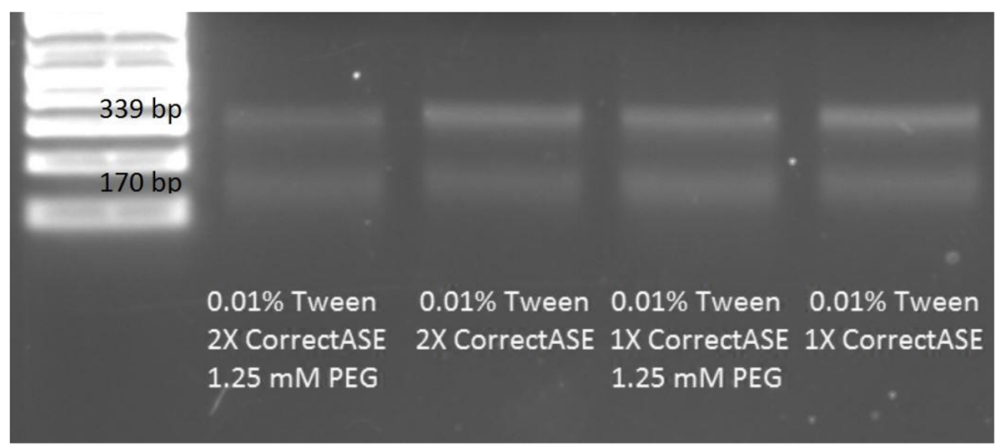

Fig. 10 CorrectASE ${ }^{\mathrm{TM}}$ optimization on the DMF platform. DNA from the reactions was separated by agarose gel electrophoresis on a $2 \%$ agarose gel

$\mathrm{Mg}^{2+}$ can be decreased because of precipitation on microfluidic surfaces, capture by chelating agents present in reagents and storage buffers, and by binding to dNTPs [37]. According to the Phusion polymerase product literature (Thermo), the optimum concentration of $\mathrm{MgCl}_{2}$ is between 0.5-1 mM. The experimental results demonstrated that the addition of $0.5-1 \mathrm{mM}$ of magnesium to the $1.5 \mathrm{mM} \mathrm{MgCl} 2$ present in Phusion HF buffer, improved polymerase activity, but this effect was inconsistent from lane to lane. However, it was shown that the synergistic effect of magnesium and PEG 8000 created favorable conditions for PCR amplification (Fig. 6).

Polyethylene glycol (PEG) is recognized as a molecular crowding agent and frequently used as a PCR enhancer and an enzyme immobilization agent [39, 40]. Molecular crowding creates the conditions similar to a natural cell environment in which the enzyme was evolved. It was reported that macromolecular crowding affects the enzyme reaction kinetics by increasing the viscosity of a medium that in turn influences the diffusion of reagents.
Also, the polymers preserve native protein conformation and facilitate binding to a substrate. It has been shown that PEG 8000 stabilized Taq polymerase at high temperatures $[39,41]$. Since Phusion is a polymerase, it is possible that PEG 8000 formed weak bonds with the enzyme and reduced hydrophobic interactions with the Teflon coating. As a result, the activity of the enzyme was increased and amplification yield was improved [42]. Consequently, microfluidic PCR is affected by adsorption as well as by interactions of reaction components with interfaces. In order to achieve amplification on the DMF, the reaction must be carried out with the final concentration of $0.1 \mathrm{U} \mathrm{\mu L}^{-1}$ of Phusion (a 5-fold increase relative to standard benchtop conditions), 0.5$1 \mathrm{mM}$ of $\mathrm{MgCl}_{2}$, and $0.625-1.25 \mathrm{mM}$ of PEG 8000 .

Improved PCR yield at $90 \mathrm{~V}$ showed that at the lower voltage, the oil film between the aqueous droplet and the Teflon coated surface stayed intact and eliminated hydrophobic interactions between the polymerase and the surface. According to Kleinert et al., the actuation voltage has a significant influence on the oil film [31]. At

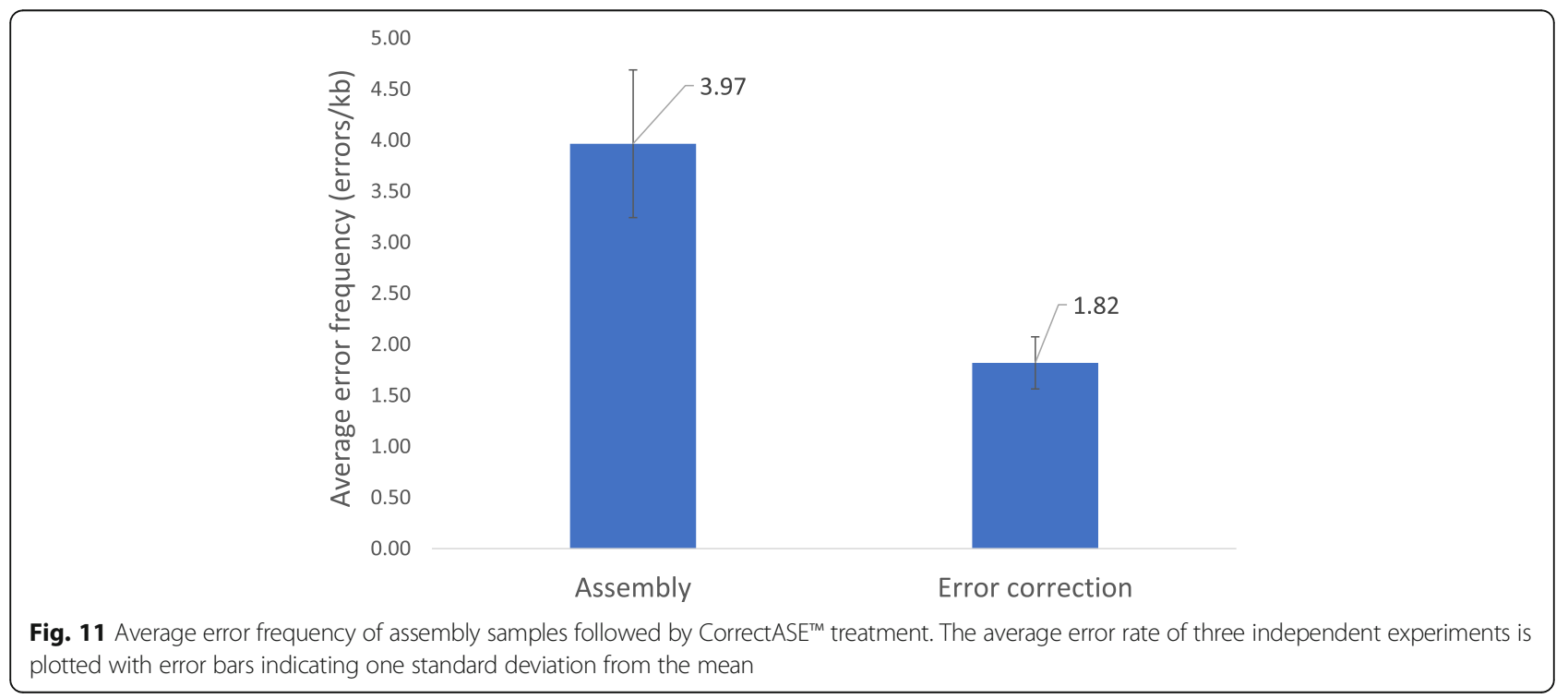


Table 3 Error analysis of DNA obtained using DMF protocol

\begin{tabular}{|c|c|c|c|c|c|c|}
\hline & \multicolumn{2}{|l|}{ Run 1} & \multicolumn{2}{|l|}{ Run 2} & \multicolumn{2}{|l|}{ Run 3} \\
\hline & Assembly & $\overline{E C}$ & Assembly & $\overline{E C}$ & Assembly & $\overline{E C}$ \\
\hline Deletions & 10 & 4 & 9 & 4 & 10 & 4 \\
\hline Insertions & 0 & 0 & 2 & 0 & 1 & 0 \\
\hline Substitutions & 3 & 3 & 1 & 0 & 0 & 1 \\
\hline Total clones sequenced & 8 & 14 & 10 & 10 & 9 & 7 \\
\hline Total of clones with correct sequences & 0 & 7 & 1 & 5 & 0 & 2 \\
\hline
\end{tabular}

high actuation voltage when the droplet moves, the film becomes unstable, breaks down, and tiny oil droplets get trapped under the aqueous phase.

In addition, excess surfactant destabilizes the oil film. Mohajeri and colleagues demonstrated that the critical micellar concentration of nonionic surfactants such as Tween 20 decreases at higher temperatures [32]. Thus, in the denaturation zone, less surfactant is necessary to reduce the surface tension. If there is an excessive amount of surfactant, the oil film becomes unstable, and the adsorption of the protein occurs, which is further enhanced at high temperatures. It is important to use lower voltage and minimize the amount of Tween 20 to avoid loss of Phusion polymerase and subsequent droplet transport failure.

\section{Optimization of microfluidic Gibson assembly}

Microfluidic DNA assembly protocols developed in this work produce results similar to the results published in the literature. Our results show that even 15 min was an acceptable length of time for an efficient microfluidic DNA assembly. In bench-top reactions, DNA assembly reactions proceed in reaction times between 15 and $60 \min [26,33,43]$.

Dilution of the assembly product prior to the PCR amplification is an additional step that should be included in a microfluidic Gibson assembly protocol. Since the goal was to assemble the product that had the minimum number of errors, it was important to remove unreacted oligonucleotides, oligonucleotide fragments, and mis-assemblies that were present at a low level before amplification. Based on these results, we kept the dilution of the assembly product no greater than 16 -fold. If the dilution step before PCR is employed, the amplifi-

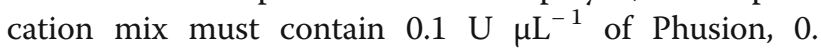
$625 \mathrm{mM}$ PEG 8000, and $0.5 \mathrm{mM} \mathrm{MgCl} 2$.

The results of the error analysis suggest that the concentration of oligonucleotides during assembly did not affect the fidelity of the resulting sequence. Both DNA assembly methods demonstrated an error frequency in the 1-10 errors $\mathrm{kb}^{-1}$ range, which was similar to the values reported in the literature for microfluidic DNA assembly [9]. For instance, Saem et al. reported 1.9 errors $\mathrm{kb}^{-1}$, Sequeira et al. reported 3.45 errors $\mathrm{kb}^{-1}$,
Kosuri et al. reported 4 errors $\mathrm{kb}^{-1}$, and Yehezkel et al. reported 2.2 errors $\mathrm{kb}^{-1}[18,44-46]$. The analysis of error types demonstrated that the majority of errors belonged to single-base deletions with a small percentage of insertions and substitutions. These results are comparable to $75.6 \%$ deletions, $2.2 \%$ insertions, and 22 . $2 \%$ substitutions, obtained by Sequeira et al. [46]. However, several clones in both data sets had misincorporated oligonucleotides. This issue could be solved by improving the design of the overlapping oligonucleotide sequences. Since the $50 \mathrm{nM}$ oligonucleotide dataset had 1.5 times more clones with mis-assemblies, degradation of some oligonucleotides by $\mathrm{T} 5$ exonuclease could be the cause of mis-incorporation. The results demonstrated that the Gibson assembly method performed on the DMF device is efficient. The error frequencies for microfluidic synthesized sequences are in line with those found for benchtop DNA synthesis in the published literature.

\section{Optimization of enzymatic error correction}

Since the best CorrectASE ${ }^{\mathrm{m}}$ activity was obtained with 0 . 01\% Tween, 2X CorrectASE ${ }^{\mathrm{m}}$, and $1.25 \mathrm{mM}$ PEG additives, the adsorption of the enzyme on the oil/water interface of the aqueous droplet is the most likely explanation of error correction in previous runs. According to Baldursdottir et al., protein molecules tend to aggregate on the oil/water interface in a multilayer. The adsorption rate is affected by the molecular weight and a saturation concentration. Large protein molecules tend to adsorb faster than small ones due to the large surface area available for contact with the interface. Also, hydrophobic proteins tend to adsorb more due to interactions with the hydrophobic coated surface [47]. If some of the protein molecules adsorb on the interface, hydrophobic and hydrophilic groups will rearrange, and it will cause the protein to change conformation, leading to a loss of activity, and the reaction will not proceed with the maximum yield.

We previously showed for PCR reactions that the presence of a molecular crowding agent such as PEG significantly increased the activity of Phusion polymerase. According to Sasaki et al., the activity of DNase I to degrade supercoiled DNA and linear DNA was improved 
in the presence of $20 \% w / v$ PEG [40]. A kinetic analysis demonstrated that the rate of the DNA cleavage reaction increased with the increasing of concentration of PEG. However, molecular crowding did not improve the activity of Exonuclease III and inhibited the activity of Exonuclease I [40]. Consequently, macromolecular crowding could be the reason why the error correction reaction was improved on the DMF platform with the addition of PEG.

Surfactants in digital microfluidic electrowetting on dielectric (EWOD) are very important. The excess of surfactant can lead to a destruction of the oil film under the droplet, which could cause the adsorption of hydrophobic molecules on the microfluidic surface. Insufficient surfactant could also cause interface instability that in turn could cause the adsorption of enzymes on the oil/water interface. Usually, to be able to generate and manipulate the droplets on DMF the concentration of Tween 20 has to be $0.01-0.05 \%$ [18, 31]. However, enzymatic reactions contain multiple components which can potentially affect surface tension. Thus, the amount of Tween 20 has to be optimized for individual reactions. It has been demonstrated in this study that even the presence of $0.001 \%$ of Tween 20 in reaction droplets in conjunction with the excess of CorrectASE ${ }^{\mathrm{Tm}}$ and PEG 8000 gives reproducible error correction results.

\section{Validation of DMF protocol for assembly with error correction}

The results of our microfluidic protocol demonstrated that some inhibition of CorrectASE ${ }^{\mathrm{mm}}$ was still occurring during error correction on the DMF platform. Lower error reduction could also be related to over dilution of error correction products prior to PCR or errors in amplification. This suggests that further optimization is possible on the DMF device.

\section{Conclusion}

Oligonucleotide assembly and error correction protocols for the Mondrian ${ }^{\text {Th }}$ digital microfluidic device were developed. The process involved automation of the polymerase chain reaction, Gibson assembly of 12 oligonucleotides, and enzymatic error correction reaction with CorrectASE $^{\mathrm{mm}}$. The final protocol consisted of the assembly of oligonucleotides, two PCR steps, and an error correction reaction. To achieve PCR amplification on the DMF platform, the reactions were supplemented with PEG, $\mathrm{MgCl}_{2}$, and 5-fold increased amount of polymerase (relative to benchtop conditions). The error correction reaction was supplemented with PEG, Tween 20, and an excess of CorrectASE ${ }^{\mathrm{mi}}$ (2-fold increase relative to benchtop conditions). The final protocol assembled DNA sequences with an average of 4 errors $\mathrm{kb}^{-1}$ and reduced errors after error correction by 2 -fold.

\section{Additional files}

Additional file 1: Video demonstration of droplet liquid handling operations used in the study. (MP4 $9178 \mathrm{~kb}$ )

Additional file 2: Sequencing reads aligned to a template. (PDF $1973 \mathrm{~kb}$ ) Additional file 3: Video demonstration of droplet movement during $300 \mathrm{~V}$ and $90 \mathrm{~V}$ PCR cycle. (MP4 19348 kb)

\section{Abbreviations}

DMF: Digital microfluidics; DTT: Dithiothreitol; EC: Error correction; NAD: Nicotinamide adenine dinucleotide; PCR: Polymerase chain reaction; PEG: Polyethylene glycol

\section{Acknowledgements}

We gratefully acknowledge the supply of electrowetting instruments and cartridges from Illumina, Inc. under a joint project agreement with Stanford University.

\section{Funding}

The study was funded by NIH grant 5R21GM104694-03.

\section{Availability of data and materials}

Small-scale Sanger sequencing data is archived with the researchers and will be made available upon request.

\section{Authors' contributions}

YK, PBG, PDW, JIG, MDA designed experiments. YK, PBG, PDW conducted research and performed experiments. YK, PBG, PDW, JIG, MDA, MAM analyzed data and wrote the manuscript. All authors read and approved the final manuscript.

\section{Ethics approval and consent to participate} Not applicable.

\section{Competing interests}

The authors declare that they have no competing interests.

\section{Publisher's Note}

Springer Nature remains neutral with regard to jurisdictional claims in published maps and institutional affiliations.

\section{Author details}

${ }^{1}$ Stanford Genome Technology Center, Stanford University, 3165 Porter Drive, Palo Alto, CA 94304, USA. ²Department of Biomedical, Chemical and Materials Engineering, San Jose State University, 1 Washington Sq, San Jose, CA 95192, USA. ${ }^{3}$ J. Craig Venter Institute, 4120 Capricorn Lane, La Jolla, CA 92037, USA.

Received: 31 August 2017 Accepted: 24 April 2018

Published online: 01 June 2018

\section{References}

1. Hutchison CA 3rd, Chuang RY, Noskov VN, Assad-Garcia N, Deerinck TJ, Ellisman MH, Gill J, Kannan K, Karas BJ, Ma L, Pelletier JF, Qi ZQ, Richter RA, Strychalski EA, Sun L, Suzuki Y, Tsvetanova B, Wise KS, Smith HO, Glass Jl, Merryman C, Gibson DG, Venter JC. Design and synthesis of a minimal bacterial genome. Science. 2016;351:6280.

2. Shendure J, Ji H. Next-generation DNA sequencing. Nat Biotech. 2008; 26(10):1135-45.

3. Hughes AR, Miklos, EA, Ellington AD. Gene Synthesis: Methods and Applications, Methods in Enzymology. 2011;498:277-309

4. Chris Voigt. Synthetic Biology, Part B; Computer Aided Design and DNA Assembly. Elsevier Press. 2011: p. 550

5. Kosuri S, Church GM. Large-scale de novo DNA synthesis: technologies and applications. Nat Meth. 2014;11(5):499-507.

6. Gibson DG: Gene and genome construction in yeast. In Curr Protoc Mol Biol. Volume Chapter 3. Edited by Ausube FM. 2011. DOl: https://doi.org/10. 1002/0471142727.mb0322s94. 
7. Gibson DG, Lei Y, Chuang R-Y, Venter JC, Hutchison CA, Smith HO, Enzymatic assembly of DNA molecules to several hundred kilobases. Nat Meth. 2009;6:343-5.

8. Gibson DG, Glass Jl, Lartigue C, Noskov VN, Chuang R-Y, Algire MA, Benders GA, Montague MG, Ma L, Moodie MM, Merryman C, Vashee S, Krishnakumar R, Assad-Garcia N, Andrews-Pfannkoch C, Denisova EA, Young L, Qi Z-Q, Segall-Shapiro T, Calvey CH, Parmar PP, Hutchison CA, Smith HO, Venter JC. Creation of a bacterial cell controlled by a chemically synthesized genome. Science. 2010:329:52

9. Ma S, Saaem I, Tian J. Error correction in gene synthesis technology. Trends Biotechnol. 2011;30(3):147-54.

10. Ma S, Tang N, Tian J. DNA synthesis, assembly and applications in synthetic biology. Curr Opin Chem Biol. 2012;16(3):260-7.

11. Lee J, Moon H, Fowler J, Schoellhammer T, Kim C. Electrowetting and electrowetting-on-dielectric for microscale liquid handling. Sensors Actuators A Phys. 2002;95(2):259-68.

12. Pollack MG, Fair RB, Shenderov AD. Electrowetting-based actuation of liquid droplets for microfluidic applications. Appl Phys Lett. 2000;77(11):1725-6.

13. Teh S, Lin R, Hung L, Lee AP. Droplet microfluidics. Lab Chip. 2008:8(2):198-220.

14. Baroud CN, Gallaire F, Dangla R. Dynamics of microfluidic droplets. Lab Chip. 2010;10(16):2032-45.

15. Song JH, Evans R, Lin Y, Hsu B, Fair RB. A scaling model for electrowettingon-dielectric microfluidic actuators. Microfluid Nanofluid. 2009:7(1):75-89.

16. Vergauwe N, Witters D, Ceyssens F, Vermeir S, Verbruggen B, Puers R, Lammertyn J. A versatile electrowetting-based digital microfluidic platform for quantitative homogeneous and heterogeneous bio-assays. J Micromech Microengineering. 2011;21(5):054026.

17. Jebrail MJ, Fau BM, Patel KD. Digital microfluidics: a versatile tool for applications in chemistry, biology and medicine. Lab Chip. 2012;12:2452-63.

18. Ben Yehezkel T, Rival A, Raz O, Cohen R, Marx Z, Camara M, Dubern JF, Koch B, Heeb S, Krasnogor N, Delattre C, Shapiro E. Synthesis and cell-free cloning of DNA libraries using programmable microfluidics. Nucleic Acids Res. 2016;44(4):e35.

19. Song $\mathrm{H}$, Chen $\mathrm{DL}$, Ismagilov RF. Reactions in droplets in microfluidic channels. Angew Chem Int Ed. 2006;45(44):7336-56.

20. Czar MJ, Anderson JC, Bader JS, Peccoud J. Gene synthesis demystified. Trends Biotechnol. 2009:27(2):63-72.

21. Huang MC, Ye H, Kuan YK, Li M, Ying JY. Integrated two-step gene synthesis in a microfluidic device. Lab Chip. 2009;9(2):276-85.

22. Kong DS, Carr PA, Chen L, Zhang S, Jacobson JM. Parallel gene synthesis in a microfluidic device. Nucleic Acids Res. 2007:35(8):e61.

23. Quan J, Saaem I, Tang N, Ma S, Negre N, Gong H, White KP, Tian J. Parallel on-chip gene synthesis and application to optimization of protein expression. Nat Biotechnol. 2011;29(5):449-52.

24. Tian J, Gong H, Sheng N, Zhou X, Gulari E, Gao X, Church G. Accurate multiplex gene synthesis from programmable DNA microchips. Nature. 2004;432(7020):1050-4.

25. Stemmer WPC, Crameri A, Ha KD, Brennan TM, Heyneker HL. Single-step assembly of a gene and entire plasmid from large numbers of oligodeoxyribonucleotides. Gene. 1995;164(1):49-53.

26. Gibson DG, Smith HO, Hutchison CA III, Venter JC, Merryman C. Chemical synthesis of the mouse mitochondrial genome. Nat Meth. 2010;7(11):901-3.

27. Yoon J, Garrell RL. Preventing biomolecular adsorption in electrowettingbased biofluidic chips. Anal Chem. 2003;75(19):5097-102.

28. Dormitzer PR, Suphaphiphat P, Gibson DG, Wentworth DE, Stockwell TB, Algire MA, Alperovich N, Barro M, Brown DM, Craig S, Dattilo BM, Denisova EA, De Souza I, Eickmann M, Dugan VG, Ferrari A, Gomila RC, Han L, Judge C, Mane S, Matrosovich M, Merryman C, Palladino G, Palmer GA, Spencer T, Strecker T, Trusheim H, Uhlendorff J, Wen Y, Yee AC, Zaveri J, Zhou B, Becker S, Donabedian A, Mason PW, Glass JI, Rappuoli R, Venter JC. Synthetic generation of influenza vaccine viruses for rapid response to pandemics. Sci Transl Med. 2013; https://doi.org/10.1126/scitransImed.3006368.

29. Prakash AR, Amrein M, Kaler KV. Characteristics and impact of Taq enzyme adsorption on surfaces in microfluidic devices. Microfluid Nanofluid. 2008; 4(4):295-305.

30. Erill I, Campoy S, Erill N, Barbé J, Aguiló J. Biochemical analysis and optimization of inhibition and adsorption phenomena in glass-silicon PCRchips. Sensors Actuators B Chem. 2003:96(3):685-92.

31. Kleinert J, Srinivasan V, Rival A, Delattre C, Velev OD, Pamula VK. The dynamics and stability of lubricating oil films during droplet transport by electrowetting in microfluidic devices. Biomicrofluidics. 2015;9(3):034104.
32. Mohajeri E, Noudeh GD. Effect of temperature on the critical micelle concentration and Micellization thermodynamic of nonionic surfactants: Polyoxyethylene Sorbitan fatty acid esters. E-Journal of Chem. 2012;9(4): 2268-74.

33. Gibson DG, Caiazza N, Richardson TH. Materials and methods for the synthesis of error-minimized nucleic acid molecules US 20130225451 A1. 2013. https:/ www.google.com/patents/US20130225451. Accessed 25 Jun 2017.

34. Fuhrmann M, Oertel W, Berthold P, Hegemann P. Removal of mismatched bases from synthetic genes by enzymatic mismatch cleavage. Nucleic Acids Res. 2005;33(6)::58.

35. Beverung CJ, Radke CJ, Blanch HW. Protein adsorption at the oil/water interface: characterization of adsorption kinetics by dynamic interfacial tension measurements. Biophys Chem. 1999;81(1):59-80.

36. Krishnan M, Burke DT, Burns MA. Polymerase chain reaction in high surfaceto-volume ratio SiO2 microstructures. Anal Chem. 2004:76(22):6588-93.

37. Wang F, Burns MA. Performance of nanoliter-sized droplet-based microfluidic PCR. Biomed Microdevices. 2009:11(5):1071-80.

38. Patel PH, Loeb LA. Getting a grip on how DNA polymerases function. Nat Struct Mol Biol. 2001;8(8):656-9.

39. Zimmerman SB, Harrison B. Macromolecular crowding increases binding of DNA polymerase to DNA: an adaptive effect. Proc Natl Acad Sci U S A. 1987; 84(7):1871-5.

40. Sasaki Y, Miyoshi D, Sugimoto N. Effect of molecular crowding on DNA polymerase activity. Biotechnol J. 2006;1 (4):440-6.

41. Saiki RK, Scharf S, Faloona F, Mullis KB, Horn GT, Erlich HA, Arnheim N. Enzymatic amplification of beta-globin genomic sequences and restriction site analysis for diagnosis of sickle cell anemia. Science. 1985;230(4732): $1350-4$.

42. Xia YM, Hua ZS, Gular E, Srivannavit O, Ozel AB. Minimizing the surface effect on PCR in PDMS-glass chips by dynamic passivation. J Chem Technol and Biotechnol. 2007:82:33-8.

43. Akama-Garren EH, Joshi NS, Tammela T, Chang GP, Wagner BL, Lee DY, Rideout lii WM, Papagiannakopoulos T, Xue W, Jacks T. A modular assembly platform for rapid generation of DNA constructs. Sci Rep. 2015; https://doi. org/10.1038/srep16836 3.

44. Kosuri S, Eroshenko N, LeProust EM, Super M, Way J, Li JB, Church GM. Scalable gene synthesis by selective amplification of DNA pools from highfidelity microchips. Nat Biotechnol. 2010;28(12):1295-9.

45. Saaem I, Ma S, Quan J, Tian J. Error correction of microchip synthesized genes using surveyor nuclease. Nucleic Acids Res. 2012;40(3):e23.

46. Sequeira AF, Guerreiro Cl, Vincentelli R, Fontes CM. T7 endonuclease I mediates error correction in artificial gene synthesis. Mol Biotechnol. 2016; 58(8-9):573-84.

47. Baldursdottir SG, Fullerton MS, Nielsen SH, Jorgensen L. Adsorption of proteins at the oil/water interface-observation of protein adsorption by interfacial shear stress measurements. Colloids Surf B Biointerfaces. 2010; 79(1):41-6.

48. Linshiz G, Jensen E, Stawski N, Bi C, Elsbree N, Jiao H, Kim J, Mathies R, Keasling JD, Hillson NJ. End-to-end automated microfluidic platform for synthetic biology: from design to functional analysis. J Biol Eng. 2016;10(1):1.

49. Shih SC, Goyal G, Kim PW, Koutsoubelis N, Keasling JD, Adams PD, Hillson NJ, Singh AK. A versatile microfluidic device for automating synthetic biology. ACS Synth Biol. 2015;4(10):1151-64.

50. Tangen U, GAS M, Sharma A, Wagler PF, Cohen R, Raz O, Marx T, BenYehezkel T, JS MC. DNA-library assembly programmed by on-demand nano-liter droplets from a custom microfluidic chip. Biomicrofluidics. 2015:9(4):044103. 